\title{
La defensa de la lengua propia en un contexto de diglosia literaria en Cataluña, Portugal y el Reino de Valencia en los siglos XVI y XVII
}

\author{
Matthias Gloël ${ }^{1}$ \\ Universidad Católica de Temuco, Departamento de Sociología \\ y Ciencias Políticas, Chile \\ Pilar Vivar ${ }^{2}$ \\ Universidad Católica de Temuco, Departamento de Lenguas, Chile
}

\begin{abstract}
Resumen
El presente artículo tiene por objetivo analizar la coexistencia del castellano con el catalán y portugués en Cataluña, el Reino de Valencia y Portugal, respectivamente, durante los siglos XVI y XVII principalmente. Para dicho fin, se utiliza el concepto de diglosia literaria, el cual parte del concepto propuesto por Fishman. Se plantean dos hipótesis que guiarán el análisis: las alabanzas de las lenguas forman parte de un fenómeno característico de aquella época, las batallas preeminenciales entre territorios en el ámbito literario, y segundo, que en mayor o menor medida hay autores en los tres territorios que rechazan el uso de la lengua de prestigio
\end{abstract}

\footnotetext{
1 Para correspondencia, dirigirse a: Matthias Gloël (mgloel@uct.cl), Montt 56, Edificio C, Temuco.

2 Para correspondencia, dirigirse a: Pilar Vivar (pvivar@uct.cl), Montt 56, Edificio U, Temuco.
} 
porque consideran que precisamente sería contrario al objetivo de glorificar su territorio.

Se evidencia que efectivamente en los tres territorios la lengua se usa como excelencia de ellos con el objetivo de destacar su alta dignidad. En Cataluña y Portugal existen varios autores que rechazan el uso del castellano para la glorificación de su propia lengua, mientras que en el Reino de Valencia la gran mayoría no considera que haya una contradicción en alabar la lengua propia usando otra.

Palabras clave: diglosia literaria, historia de la lengua, historia moderna.

\title{
The DEFENSE OF THE NATIVE LANGUAGE IN A CONTEXT OF LITERARY diglossia in Catalonia, the Kingdom of Valencia and Portugal IN THE $16^{\mathrm{TH}}$ AND $17^{\mathrm{TH}}$ CENTURIES
}

\begin{abstract}
The purpose of this study is to analyze the coexistence of Spanish with Catalan and Portuguese respectively in Catalonia, the Kingdom of Valencia and Portugal in the $16^{\text {th }}$ and $17^{\text {th }}$ century. Therefore we use the concept of literary disglossia, based on the concept proposed by Fishman. We propose two hypotheses to guide the analysis: first, the language praises are part of a typical phenomenon of that time, the literary pre-eminence battles between territories and second, that there are, to a higher or to a lower degree, authors in the three territories who reject to use the prestigious language, because they consider that this would jeopardize the purpose of glorification of the territory. Results show that in the three territories the language is used indeed as an excellence of it in order to emphasize its dignity. In Catalonia and Portugal there are several authors who reject the use of Spanish to glorify their own language, while in the Kingdom of Valencia most authors do not see any contradiction between praising their language, but doing it in another one.
\end{abstract}

Keywords: Literary diglossia, Language history, Early Modern history.

Recibido: 27/03/19

Aceptado: 30/01/20 


\section{INTRODUCCIÓN}

El presente artículo tiene por objetivo comparar la coexistencia del castellano con el portugués y con el catalán en Valencia, Cataluña y Portugal durante los siglos XVI y XVII en situación de diglosia literaria, los que habitualmente se solían investigar de forma individual. El concepto de diglosia literaria parte de la teoría ideada por Fishman (1967). Sin embargo, tal concepto no es capaz de explicar ciertos elementos que aparecen en obras literarias de los siglos XVI y XVII: por un lado, la glorificación de la lengua desprestigiada por parte de los autores, $\mathrm{y}$, por otro, la existencia de autores que rechazan el uso de la lengua de prestigio, ya que consideran que dicho uso constituye un perjuicio a la lengua propia e incluso a su territorio, por lo cual les resulta imposible no usarla.

Para analizar dichos dos fenómenos, planteamos un análisis a partir de dos hipótesis: primero, que los discursos acerca del uso de la lengua se enmarcan en lo que Antoni Simon i Tarrés (2005: 105) ha denominado "batallas preeminenciales", las cuales constituían batallas literarias sobre cuál reino hispano era el más digno y más noble. Otros campos clave de dichas batallas eran la historia, la antigüedad, el clima o la calidad de la tierra, para nombrar solo algunos (Gloël 2014). Segundo, debido a la castellanización mucho más avanzada de las élites valencianas, respecto a las catalanas y portuguesas, que el rechazo al uso del castellano como lengua literaria y de prestigio se encuentra mucho menos presente en autores provenientes del Reino de Valencia que en Cataluña y Portugal.

Para probar nuestras hipótesis, explicaremos dentro del marco teórico brevemente el contexto sociolingüístico de la primera Edad Moderna, como también los conceptos de diglosia y diglosia literaria.

\section{MARCO TEÓRICO}

\subsection{CONTEXTO HISTÓRICO}

La división de la península ibérica en dos estados nacionales (España y Portugal) marcó fuertemente la historiografía (incluida la historia de la lengua) de ambos países durante mucho tiempo. Se solía interpretar la historia de los siglos XVI-XVIII con una visión retrospectiva que daba por 
establecida dicha división de la península ya para la Edad Moderna. Aunque dicha visión en gran medida ya se encuentra superada (Elliott 1992; Torres Sans 2004; Cardim 2013), esta larga tradición sigue dejando su impronta en la sociolingüística.

Muchas investigaciones acerca de aquella temática, por un lado, siguen vinculadas al paradigma nacional y, por otro lado, suelen investigar solo uno de los territorios mencionados. El motivo del segundo punto podría hallarse precisamente en el primero. El hecho de que en Portugal la diglosia haya desaparecido entre fines del siglo XVII y mediados del XVIII, mientras que en Cataluña y Valencia haya seguido vigente hasta el siglo XXI, puede haber provocado que apenas se hayan relacionados en cuanto a diglosia. Sobre todo en Portugal aún sigue siendo muy habitual considerar al vecino español como un conjunto monolítico ya en la Edad Moderna, por lo cual solo existe una oposición entre lo portugués y lo español, también en términos lingüísticos (Buescu 2004; Castro 2002; Vásquez Cuesta 1988). También en Cataluña suele haber un enfoque único al propio caso, incluyendo a veces el caso valenciano, ignorando, en cambio, el portugués. (Torrent 1989; Pitarch 2000; Marfany 2001; Peña Díaz 1997)

Eulàlia Miralles (2010: 77), en su trabajo sobre el cronista catalán Jeroni Pujades presenta la diglosia literaria como un fenómeno particular de la Cataluña moderna, en el cual las personas decidían cambiar la lengua materna catalana por el castellano. La autora relaciona el uso de una lengua u otra con el patriotismo, ejemplificado en los textos de Pujades. Las convicciones patrióticas de este autor habrían ido en detrimento con el tiempo, debido a que de joven solía publicar en catalán y más tarde cada vez más en castellano. (Miralles 2010: 85)

Desde una perspectiva más general, María Sol Teruelo Núñez (1985) describe a los autores portugueses, con especial atención a los años de la pertenencia del reino luso a la monarquía hispánica (1580-1640). Para su análisis divide a dichos autores en dos grupos: el primero constituido por aquellos que escribían en castellano, quienes -según la autora- tendrían un "deseo e interés común" porque deseaban la divulgación de sus obras fuera de Portugal; mientras que en el segundo grupo se encuentran los autores que escribían en portugués, los cuales serían guiados por un "nacionalismo lingüístico" a pesar de que estaban conscientes de que su elección por el portugués los llevaba a un aislamiento cultural. (Teruelo Núñez 1985: 333)

Sobre la situación lingüística en la España de los siglos XVI y XVII, Werner Bahner (1956) comenta, a propósito del autor valenciano Martí de Viciana, que publicar en valenciano o justificar la publicación en castellano se trataría de un regionalismo del cual Viciana sería un ejemplo idóneo a apuntar. 


\subsection{Contexto sociolingüístico}

No todas las lenguas vulgares de la península ibérica se convirtieron en lenguas literarias, específicamente, en la corona de Castilla lenguas como el leonés o el asturiano no pasaron de ser lenguas orales. Una excepción constituye el galaico-portugués, cuya lírica tuvo un gran auge entre 1200 y 1350 aproximadamente (Vilavedra 1999: 43-44). En la Edad Moderna, en cambio, el gallego no logra imponerse mayormente como lengua literaria. Si bien hay excepciones como Gregorio de Lobariñas Feijoó (1616; 1626) que defiende el uso del gallego en sus obras, la mayoría de los escritores gallegos no prestaron mayor atención a su lengua. (Bouza 2009: 30)

A diferencia de lo anterior, en la Corona de Aragón la situación de las distintas lenguas era diversa. Los aragoneses no desarrollaron la conciencia necesaria a favor de su lengua para querer elevarla a lengua literaria, siendo de esta manera los propios hablantes quienes contribuyeron a su decadencia. Con respecto a lo anterior, Francho Nagore (1977: 14) estima que alrededor de 1500, las elites urbanas en Aragón ya se encontraban castellanizadas. A eso conviene añadir que, ya durante los siglos XIII y XIV, el catalán fue la lengua predominante de la Corona de Aragón, a pesar de que el aragonés también fue una de las lenguas oficiales junto con el catalán y el latín. (Lledó-Guillem 2018: 33)

En el caso del catalán, a diferencia de Cataluña, en el Reino de Valencia se produjo un proceso de aceptación del castellano como lengua de uso literario mucho más rápido después de la rebelión de las Germanías (1520-1522). Los nobles vencedores para distinguirse de los agermanados adoptaron la lengua del rey que les había apoyado (Carbonell 1979: 93). Sin embargo, en el siglo XV, el catalán había tenido su época dorada como lengua literaria con autores como Joanot Martorell (1410-1465) y Ausiàs March (1400-1459).

En Cataluña y Portugal, a pesar de una presencia importante del castellano, las respectivas lenguas siguen también muy presentes en el ámbito literario en el siglo XVI. En los tres casos (Cataluña, Valencia y Portugal), se puede identificar, por lo tanto, una diglosia en el ámbito literario, ya que el uso de varias lenguas estaba limitado a las élites y a los letrados. Para el caso portugués, el proceso de influencia castellana se inicia mucho antes que la unión dinástica de $1580^{3}$, por lo que la diglosia no es producto de circunstancias políticas concretas. Además, el catalán y el portugués e incluso

\footnotetext{
Véase, por ejemplo, el caso de Gil Vicente (1465-1536) quien escribió buena parte de su obra en castellano o bilingüe portugués-castellano.
} 
el aragonés nunca dejaron de ser lenguas institucionales en aquellos siglos, por lo que no se puede decir que hubiera decisiones políticas detrás de las actitudes de los autores.

\subsection{Diglosia y diglosia Literaria}

El concepto de diglosia es acuñado principalmente por Charles Ferguson (1959) y Joshua Fishman (1967). Para Ferguson (1959) originalmente, diglosia define la coexistencia de dos variantes de una misma lengua, siendo una la Variedad Alta (A) para situaciones formales y otra la Variedad Baja (B) para situaciones informales. Los hablantes de una comunidad diglósica suelen considerar la variante A como superior y prestigiosa y que tiene más elegancia y lógica (Fasold 1996: 74). Fishman recoge la teoría de Ferguson, sin embargo, se muestra mucho más abierto en cuanto a las posibilidades de situación diglósica. Para Fishman (1972: 92) no se debe tratar necesariamente de dos variantes de una sola lengua, sino que el fenómeno de diglosia existe cuando hay "functionally differentiated language varieties of whatever kind". La gran modificación que realiza Fishman (1967) al concepto de diglosia de Ferguson consiste en establecer diferencias claras entre diglosia y bilingüismo ${ }^{4}$. Mientras el bilingüismo vendría siendo un fenómeno a nivel individual, la diglosia, en cambio, se presenta a nivel de sociedad. Ambos fenómenos pueden coexistir como también puede haber contextos de uno de los dos sin la presencia del otro.

Este concepto de Fishman resultaría aplicable a la situación literaria de la península ibérica en la época moderna, debido a que la relación entre el castellano y el portugués/catalán sería la de una lengua de prestigio (castellano, lengua A) y una lengua desprestigiada en el ámbito literario (portugués, catalán, lengua B). De hecho, Filipe Alves Moreira (2014: 383) ya ha usado el término de diglosia para el caso portugués, señalando que "o uso do castelhano por portugueses foi de tal forma intenso que poderemos falar de «diglossia», considerando que o português chegou a estar socialmente conotado com as franjas mais pobres e/ou iletradas da população". También el autor español Alonso Romo (2000: 146) caracteriza el tiempo de la unión a partir de 1580 como una diglosia, en la cual dominaba el castellano, mientras que el portugués estaría relegado al estado de una lengua popular. Para el caso catalán, Joan-Lluís Marfany (2008: 102) señala

$4 \quad$ Acerca de las diferencias de ambos autores, véase además Spolsky 2011. 
que se trata de una diglosia de las élites, dado que "a les societats d'Antic Règim la pràctica lingüística està completament $\mathrm{i}$ expressament condicionada per la classe". También Eulàlia Miralles (2010: 77) usa diglosia para describir la coexistencia del catalán y castellano en la Cataluña moderna.

Aplicando las categorías de Fishman se podría hablar en los tres territorios a tratar de diglosia sin bilingüismo, ya que solo un grupo reducido de la sociedad maneja la lengua A, el castellano. Sin embargo, la gran mayoría de las personas que no domina la lengua A es iletrada. Por lo tanto, contemplando solamente la población letrada como un grupo aislado, también tendría cabida hablar de diglosia como bilingüismo, ya que casi todos dominan tanto la lengua A como la B.

\section{RESULTADOS}

\subsection{LAS ALABANZAS DE LA LENGUA EN EL CONTEXTO DE LAS BATALLAS PREEMINENCIALES}

Como hemos mencionado previamente, las llamadas batallas preeminenciales en el ámbito literario en los siglos XVI y XVII principalmente consistían en la exaltación de distintos aspectos acerca de un territorio para evidenciar su mayor dignidad frente a otros. Como apunta Simon i Tarrés (2005: 105), "les 'batalles preeminencials' entre regnes van ser ben presents en la literatura histórica, jurídica i política medieval i renaixentista". Por ejemplo, la población de España después del diluvio por la mítica figura de Tubal, es narrada bien diferente de las crónicas de los distintos reinos españoles, lo cual incluye Portugal (Gloël 2017). Las crónicas de cada territorio reclamaban la llegada e inicio de la población para su territorio, con lo cual adquirirían una mayor antigüedad y con ello mayor dignidad frente a los otros reinos.

Lógicas parecidas se encuentran a nivel jurídico acerca de las mejores leyes en cada reino, el mejor sistema de gobierno o bien en los diversos aspectos de la naturaleza que se encuentran en las descripciones de territorios o ciudades. Estos aspectos se convierten en excelencias de un territorio y los autores los suelen comparar con los otros reinos españoles para argumentar que el propio sería el más digno de todos (Gloël 2014: 143-183). En muchos casos, la comparación en los reinos periféricos se hace expresamente con el de Castilla, al ser Castilla el centro de la monarquía en cuanto a que el rey solía residir en dicho reino y que la mayoría de las posiciones clave de la monarquía (virreyes, embajadores, consejeros, etc.) provenían de ahí. 
Como hemos indicado al inicio, creemos que también se usaba la lengua en este contexto, como herramienta para enaltecer el territorio. En un contexto de diglosia se esperaría que se publiquen principalmente elogios hacia la lengua de prestigio, en este caso el castellano. Lo anterior efectivamente se hizo por parte de varios autores castellano. Así, Fernando de Herrera (1580, citado en Pastor 1929: 101) describe la lengua castellana como "grave, religiosa, onesta, alta, manifica, suave, tierna, afetuosisima, i llena de sentimientos, i tan copiosa i abundante" y señala que ninguna otra se podría comparar con ella.

Aproximadamente un cuarto de siglo más tarde, Bernardo de Alderete (1606/1993: sin paginación) en el prólogo de su obra Del origen y principio de la lengua castellana ò romance qui oi se usa en España refiere un listado de características positivas que debe poseer una lengua: "La propiedad con copia, i abundancia de vocablos, la dulçura junta con gravedad, la elegancia acompañada de facilidad, i otros ornamentos semejantes son los que honrran, i dan precio, i estima a una lengua", las cuales sería todas muy características de la lengua castellana.

Conscientes de la asimetría existente entre el castellano y las demás lenguas ibéricas, los autores castellanos que se dedican a escribir sobre las lenguas, expresan una clara superioridad de su lengua sobre las otras. Así, Francisco Cepada (1643:3) escribe que "la lengua Castellana en la elegancia, en la propiedad, en lo limado, en la abundancia, y gracia, en la magestad y gravedad, en lo mucho que pueden comprehender sus frases, y modos de decir", con lo cual sería superior a todas las otras lenguas provenientes del latín.

Otros autores incluso niegan la simetría de las distintas lenguas españolas como hijas del latín. Alderete (1606: 165) explica la existencia del catalán y del portugués como lenguas derivadas del castellano. Ésta se habría mezclado con el francés, tanto en Portugal como en Cataluña, lo cual habría dado lugar a estas variantes corruptas del castellano. Para Gregorio López Madera (1601: $70 \mathrm{v}$.), el castellano ni siquiera provendría del latín, sino que se trataría de la lengua originaria de España como una de las 72 lenguas resultantes de la confusión de lenguas provocada por la construcción de la Torre de Babel. Las otras lenguas españolas, en consecuencia, serían "subalternas y corrompidas della", debido a la mezcla con lenguas extranjeras. Si bien muchas veces se ha explicado que la derivación del latín implicaría gloria para las lenguas derivadas de él (Guitarte 1986; Mignolo 1995), Lucia Binotti (1995: 42) señala que este argumento podría tener justamente el efecto contrario al dejar en evidencia la inferioridad de las lenguas vulgares, ya que la derivación se habría producido mediante corrupción. 
Damasio de Frías ${ }^{5}$ (1929: 269) describe de una manera un poco más detallada a las otras lenguas ibéricas: la vizcaína serviría solamente para los "vizcaínos y su cólera, que sin duda parecen la cólera de España", una lengua poco útil para el habla e imposible para la escritura. El valenciano sería una lengua infantil, para gente no adulta. El catalán lo describe como seco, poco cultivado y algo bárbaro, por lo que sería una lengua solo para hombres. El portugués, en cambio, al ser dulce sería una lengua para mujeres y a la vez "algo vacía" y que posiblemente "le pegó el vicio de la nación".

Frente a la posición anterior surgen las alabanzas hacia lenguas como el catalán o el portugués como una defensa de la lengua propia (Carvalhão Buescu 1983: 225; Tres 1996: 28; Peña Díaz 1997: 152). Algunos autores tienen efectivamente este propósito de defender su lengua, como es el caso de Pêro de Magalhães de Gândavo (1574) con su Diálogo em defensão da lingua Portuguesa, el cual se publica como anexo a la obra Regras que ensinam a maneira de escrever e a ortografia da língua portuguesa. Se trata de un diálogo entre un castellano y un portugués que discuten sobre cuál de las dos lenguas es mejor. Cada uno habla en su lengua, con lo cual el autor se opone a la norma implícita de usar la lengua de prestigio, en este caso el castellano. El castellano expresa los prejuicios contra la lengua portuguesa, como por ejemplo, que ésta sería la "mas tosca y grossera del mundo". El portugués rechaza dichos prejuicios y destaca en cambio las excelencias de la lengua portuguesa, como en este ejemplo que señala que sería "tão excellente assi na prosa como no verso" que solamente el latín podría ser algo superior. (Magalhães de Gândavo 1574/1981: 42-43)

Este tipo de defensa se puede ubicar también en las referidas batallas preemienciales, ya que al igual que en la lógica de la época, una menor antigüedad sería indicio de un territorio menos digno, también una lengua menos digna indicaría lo mismo. Asimismo el autor catalán Andreu Bosch (1628) en su Summari, Index, o Epitome dels admirables, y nobilissims titols de honor de Catalunya, Rossello, y Cerdanya refuta argumentos castellanos sobre la inferioridad del catalán. El autor expone en su obra una serie de dignidades del territorio catalán, de índole histórica, de geografía, de nobleza y también de lengua. Por ejemplo, refiere "lo error comu que la llengua Castellana li porta [a la catalana] aventatge per esser la nostra mes curta" (Bosch 1628: 28). El autor convierte esta supuesta desventaja en una excelencia, señalando que no por eso puede ser considerada inferior, sino

Apenas se tiene información cierta sobre la vida de Frías ni fechas exactas de la redacción de sus obras; Rubio González (1988: 148) señala que vivió en Valladolid en la segunda mitad del siglo XVI. 
"ans mes propria per traduyr, y prompta per parlar en moltes vocables se trobarà mes llarga y propria”. (Bosch 1628: 29)

Muchos autores y sus alabanzas, en cambio, no tienen ninguna intención defensiva, sino que buscan enaltecer su lengua y muchas veces presentarla como la más digna de toda España o incluso del mundo. El propio Bosch compara los orígenes del castellano y del catalán señalando que mientras la primera "antiguament era la mes impropria y barbara", la segunda ya habría nacido "tant graciosa, cortesana, sentenciosa y dolça" (Bosch 1628: 18-19). Así, el autor destaca la mayor antigüedad que tiene el catalán como lengua digna frente al castellano.

Para el caso del portugués, Manuel Severim de Faria (1624) elabora un trabajo sistemático para mostrar que la portuguesa es la lengua más digna de todas. El autor establece cinco criterios para medir la perfección de una lengua: primero, "ser copiosa de palabras", seguido por "boa de pronunciar", tercero, breve no dizer, cuarto, "que escreva o que falla" y finalmente, "que seja apta pera todos os estillos" (Severim de Faria 1624: 65). Los mismos criterios los copia unos años más tarde António de Sousa de Macedo (1631: 236v.) en su obra Flores de España, excelencias de Portugal, la cual justamente incluye también la lengua como uno de los criterios de excelencia para un territorio (Gloël 2020). Antes de aplicar estos criterios en detalle, el autor ya adelanta su conclusión: "Todas estas qualidades tiene la habla Portuguesa en gran estremo, como en cada una iré probando". (Sousa de Macedo 1631: 237)

El hecho de que Sousa de Macedo redacte su obra en castellano llama la atención acerca de otro fenómeno muy propio de esos siglos y que no encaja en el concepto de una situación diglósica: muchos autores eligen la lengua de prestigio, justifican su elección y prácticamente en el mismo momento alaban a la lengua $\mathrm{B}$, su lengua materna que ellos mismos han descartado como vehículo de publicación. Dicho fenómeno se encuentra presente en los tres reinos que se tratan aquí, en los cuales se detectan distintos grados de alabanza de la propia lengua.

El primero y más elemental es negar que se tenga en menos la propia lengua, es decir, negar que sea una lengua sin prestigio. Para ello se encuentran ejemplos a lo largo de los siglos XVI y XVII. Antoni Beuter (1546: 2), cronista proveniente del Reino de Valencia, señala en su Primera parte de la coronica general de toda España, y especialmente del Reyno de Valencia que el uso del castellano por su parte "no se le haze a la lengua Valenziana perjuyzio en ello, ni pierde por ello el ser habla polida, dulce, y muy linda, que con brevedad moderada exprime los secretos y profundos conceptos del alma, y despierta el ingenio a vivos primores, de donde le resulta un muy esclarecido lustre". Conviene señalar que se trata de una 
traducción hecha por el propio autor de su obra publicada en catalán Primera part de la Història de València (1538/1995).

El catalán Lluís Ponç d'Icard (1572: sin paginación) en su crónica sobre la ciudad de Tarragona declara que el haber escogido el castellano no implica que lo considere mejor lengua que el catalán pero el hecho de que es la lengua del rey, más la mayor difusión habrían provocado su elección. Dionysio Hieronymo de Iorba (1589: sin paginación), quien al igual que Ponç d'Icard ${ }^{6}$ tradujo su manuscrito catalán para publicarlo en castellano para su impresión. Sin embargo, alega que ello no significa que considere el catalán inferior en aspecto alguno, sino que su único motivo habría sido el deseo que se lean las excelencias de Barcelona en muchas partes (Iorba 1589: sin paginación). En este caso se mezclan las excelencias de la ciudad con la lengua como excelencia propia del mismo territorio. El portugués Pedro Barbosa Homem (1627: sin paginación) explica que haber dejado su propia lengua no quiere decir que le tenga "menor estimacion de la essencial bondad" al portugués en comparación con el castellano. Como Ponç señala que su obra está dirigida al rey, por lo cual habría decidido redactarla en el idioma "que en efeto le es materno". A diferencia de las obras de corte más historiográfico, su Discursos de la juridica, y verdadera razon de estado, formados sobre la vida, y acciones del Rey don Juan el II de buena memoria, Rey de Portugal, llamado vulgarmente el Principe Perfecto es un texto político y jurídico para ofrecerle al rey un modelo de gobernar y a la vez un estudio acerca de la razón de estado como forma de gobierno.

Estevan de Corbera (1678) $)^{7}$ en su Cataluña Ilustrada hace referencia a la obra de Bosch previamente referida. Lamenta la poca distribución de la obra de Bosch por estar escrita en catalán, afirma, sin embargo, que dicho autor habría mostrado las "riquezas y ventajas" que posee el catalán, con las cuales no sería inferior a ninguna otra lengua vulgar (Corbera 1678: 8). El autor trata una serie de excelencias del territorio catalán, históricas como geográficas, y también incluye la lengua como otra excelencia más del territorio.

Otros autores no se contentan con simples alabanzas o con destacar que su lengua no es inferior a la supuesta lengua de prestigio. Uno de los casos más emblemáticos es el valenciano Martí de Viciana con su Libro de alabanças de las lenguas hebrea, griega, latina, castellana y valenciana (1574). Si bien el autor alaba la lengua castellana, señala después que el

El manuscrito original en catalán fue publicado en 1984 por Eulàlia Duran.

La obra es póstuma; el autor murió en 1635. 
valenciano le sería muy superior, lo cual explica a partir de la formación inicial de ambas lenguas. Mientras el valenciano provendría "por derecha linea y propagación" del latín clásico, el castellano tendría su origen en un latín ya corrompido, una "madre bastarda", por lo que muchas palabras valencianas serían mucho más parecidas al latín que en el castellano (Martí de Viciana 1574: sin paginación). Cabe señalar que el autor en toda su vida no publicó ningún texto en valenciano sino que siempre tradujo sus manuscritos valencianos al castellano para su publicación. (Escartí 1995: 15)

El catalán Àngel de Pas (1579: sin paginación), en su prólogo al lector de la Primera parte de los discursos espirituales sobre la inscripción, prólogo, y quatro primeros capítulos de la regla de los terceros, pide perdón por "haverme abaxado à escrivir en Romance Castellano, y siendo de nación Cathalana, y no criado en castilla: pues lo hago por mas aprovechar a los que esta obra leyeren: siendo lengua en los tiempos de hagora mas comun". Dicha excusa deja entrever que en principio Pas considera el catalán superior al castellano pero aun así lo escoge por su mayor distribución, por lo cual considera haberse "abaxado" en cuanto a la lengua.

Marco Antonio Ortí publica en 1640 su obra Siglo quarto de la conquista de Valencia, en la cual describe las fiestas realizadas en 1638 por motivo del cuarto centenario de la conquista de Valencia por Jaime I en 1238. En su prólogo escrito en valenciano justifica la redacción de la obra en castellano, admite que su propio idioma "es tan rich, y abundant de veus propies, $\mathrm{y}$ frases tan significatives, que pogera ab ell millor y mes clarament pintarse tot lo ques feu en esta ocasio" (Ortí 1640/2005: sin paginación). Por lo tanto, Ortí afirma haber sacrificado calidad lingüística al renunciar al valenciano por el castellano, con el cual dice no se pueden explicar las cosas con tanta claridad. Y continúa el autor: "Pero encara que en esta llengua participara aquest llibre de tanta elegancia com en la Llatina li poguera donar lo mateix Cicero, solament servira pera els Valencians" (Ortí 1640/2005: sin paginación). Y por esta razón, a pesar de que según Ortí el valenciano tiene la misma elegancia que el latín clásico de Cicerón, lo habría publicado en castellano.

También en Portugal se encuentra este tipo de argumentación. Bernarda Ferreira de Lacerda (1618) se disculpa en su España libertada por no escribir en la lengua del "reyno Lusitano, que de muchos de Europa eres corona". "Confiesso de tu lengua que merece mejor lugar despues de la Latina", continúa la autora y alega que son justamente la "pronunciacion, y dulces modos" que les complicaría la comprensión a los foráneos. Y como la castellana es mucho más fácil ("para todos") habría decidido redactar su obra en ella. (Ferreira de Lacerda 1618: 1v.-2)

Por su parte, António de Sousa de Macedo (1631) va más allá todavía que muchos otros autores. Como ya hemos visto, su obra es otro ejemplo más de 
incluir a la lengua como excelencia de un territorio. El autor, no solo alaba el portugués y deja entrever una superioridad sobre el castellano, sino que desprestigia de cierto modo la lengua vecina. El autor explica que "no dexo yo la Portuguesa por parecerme inferior, antes assi por tenerla por tan excelente" (Sousa de Macedo 1631: 235), lo cual podría considerarse aún dentro de las alabanzas habituales hacia la lengua propia. Sin embargo, en la siguiente página, Sousa de Macedo retoma ese argumento y le agrega el desprecio hacia el castellano, explicando que habría escogido el castellano para su obra y no el portugués, el cual "como cosa tan buena no es tan entendida como lo fuera siendo mala" (Sousa de Macedo 1631: 235v.). En definitiva, aquí el autor relaciona la calidad de una lengua con su grado de difusión, siendo un menor grado señal de mayor calidad, lo cual también explicaría las dificultades de aprender una lengua de calidad alta. El castellano queda caracterizado como una lengua fácil, de gran difusión y, por lo tanto, de baja calidad ("mala"), mientras el portugués justo por su excelencia causa dificultades entre los no portugueses.

\subsection{LA DEFENSA DEL USO DE LA LENGUA PROPIA}

En aquella época era habitual que en Cataluña, Valencia y Portugal los autores justificasen su elección lingüística en sus prólogos o incluso dentro de sus obras, tanto en caso de usar el castellano como el de la lengua propia. En cuanto al uso del castellano, el argumento más usado por los autores que decidieron publicar en dicha lengua era el de la universalidad de ella, con lo cual las obras llegarían a tener más lectores, contrastándola a menudo con la poca distribución que tienen obras publicadas en su propia lengua. Vicent Josep Escartí (1995: 14) ha denominado este fenómeno la "escusa fàcil de la universalitat" del castellano, dejando entrever que solo se trataría de un pretexto justificativo.

Con este argumento precisamente justifica el ya mencionado Beuter la traducción de su primer parte de su crónica:

Imprimiose pues en lengua Valenciana, como yo la compuse, y pienso que hizo algun provecho en nuestra tierra. Y según de que algunos curiosos fue recogida en Aragon y Castilla, parecio que con alguna poca de mejoria se podria embiar por toda España, a dar lengua (como de camimo) en las ciudades della de muchas antiguedades que alli acontecieron en tiempo de Romanos, y antes, y después dellos. Para lo qual era necessario proveerle de lengua Castellana, con que fuesse entendida en los lugares que no entendian la Valenciana". (Beuter 1563: 2) 
Este mismo argumento lo emplean de forma muy parecida, el catalán Estevan de Corbera y el portugués Manuel de Faria e Sousa. En su Cataluña Ilustrada, Corbera hace referencia a crónicas catalanas ya existentes escritas en catalán. Alaba la gran calidad de autores como Jeroni Pujades (1568-1635) y Andreu Bosch (1586-1631). Sin embargo, lamenta la poca difusión que han tenido ambos autores y el poco conocimiento que los extranjeros tienen de ellos. La conclusión de Corbera (1678: 6) es que lo anterior ocurrió "por haverla escrito en lengua Catalana, y mal reçebida dela emulacion de sus conaturales". De forma parecida se lamenta Faria e Sousa (1678: 1) que muchas cosas de la historia portuguesa y las crónicas sobre ellas hayan quedado olvidadas, "ya porque no se han impresso las mas destas Historias, ya porque las impressas estan en Portugues" ". Ambos autores, por lo tanto, responsabilizan su propia lengua respectivamente por el hecho de que las crónicas que se han publicado en sus reinos no o apenas se hayan difundido.

En este sentido, hay incluso autores que consideran que al escoger la lengua castellana le hacen un gran favor al territorio o ciudad cuya historia relatan. Así es el caso de Lluís Ponçd'Icard y su Libro de las grandezas y cosas memorables dela Metropolitana Insigne y famosa Ciudad de Tarragona. Según el autor, hubiese sido un "agravio que hazia a la dicha ciudad" si solo hubiese publicado para el público catalán (Ponçd'Ícard 1572: sin paginación). El ya referido autor portugués António de Sousa de Macedo (1631: sin paginación) explica que su obra trata "lo mejor de Portugal en lengua Castellana". Más adelante, en un capítulo destinado a la lengua, señala "el amor de mi patria me incite a publicar sus excelencias por todo el mundo, dexados todos los respetos, me ha parecido mejor medio hazerlo en lengua Castellana, que acertó ser mas conocida en Europa" (Sousa de Macedo 1631: 235v.). De la misma forma señala Pedro Barbosa Homem (1627: sin paginación) que su elección por el castellano es ventajosa para Portugal porque hará su honor y derecho más conocidos en el mundo. Argumenta que el portugués es "entendido, y hablado de muy pocos", mientras el castellano "lo es de casi todos".

Frente a estos autores provenientes de Cataluña, Valencia y Portugal quienes optan por el castellano, hay otros que adoptan una posición contraria, la cual también justifican como parte de sus obras, si bien en diferente intensidad. Como ya hemos mencionado es en el reino de Valencia donde la castellanización fue más fuerte. Son muy pocos y más bien tempranos los autores como Jaume Roig que deciden escribir en valenciano. En un prólogo

8 La obra es póstuma; el autor murió en 1649. 
anónimo a su Llibre de consells i de les dones (publicado en 1531, el autor ya había muerto en 1478) dice lo siguiente: "Criat en la pàtria/que es diu llemosina no vol aquest llibre mudar son llenguatge. De vena tan fèrtil/és nat i tan fina, Que d'ell brolla aigua/excelsa i divina i el veus del ingenis/molt dolç companatge" (citado según Pitarch 1972: 36). Este libro, que constituye esencialmente una autobiografía acerca de las experiencias del autor con las mujeres y caracterizado como misógino por la historiadora Jean Dangler (2001: 51), contó con dos ediciones más en 1561, ellas también en catalán.

Resulta necesario explicar brevemente el término llemosina (lemosina en castellano), ya que precisamente en el siglo XVI cuando se redacta este prólogo, el significado de la palabra estaba cambiando respecto al que tenía durante la Edad Media (Lledó-Guillem 2008: 57-58). Como explica Germà Colon (1978: 39-40), desde mediados del siglo XII se usa como lengua escrita para poesía lírica, hecha en buena parte por los trovadores de la provincia de Lemosín. Este significado de literatura occitana cambia en el siglo XVI y lengua lemosina pasa a referirse a la literatura catalana de los siglos previos (Lledó-Guillem 2018: 113-115), lo cual explica esta referencia realizada en 1531 para caracterizar un texto del siglo XV.

Esta posición arriba defendida, sin embargo, constituye ya una excepción en el Reino de Valencia del siglo XVI. Pitarch (1972: 31) alude en este contexto a las "fabuloses possibilitats" que habrían ofrecido el imperio español y la lengua castellana y las que las élites valencianas querían aprovechar.

En Cataluña y Portugal, en cambio, se encuentran a menudo justificaciones de escribir en su propia lengua, las cuales van de la mano con el rechazo explícito a otras posibles lenguas de publicación, específicamente el castellano como nueva lengua de prestigio y el latín como lengua clásica de prestigio. Así, el portugués Francisco Rodrigues Lobo (1990: 190) se posiciona en su obra Corte na aldeia (1619) contra el uso del latín. Según él, el uso de palabras latinas llevaría a una lengua mixta y el portugués por sí solo ya sería "de muito bom metal", el cual con una mezcla solo perdería calidad. Se trata de una novela pastoril, en la cual el autor lamenta la ausencia de la corte real y que se convirtió en el símbolo del Portugal de los Austrias como reino sin rey. (Valladares 2000: 40)

El también portugués Amador Arraiz (1604: sin paginación) a su vez rechaza la opción de escribir sus Diálogos, los cuales abarcan temáticas de diversa índole, en latín u otra lengua extranjera, optando por el portugués: "Não os quis escrever em lingoa Latina, mas em a nossa Portugueza, porque alem desta com sua grave brevidade ser accommodada ao que nelles se trata, minha principal tenção foy aproveitar a todos os nossos que nam tem noticia de lingoas estranhas". Por lo tanto, además declara que su objetivo principal 
son los lectores portugueses incluyendo los letrados sin ser eruditos, es decir, conocedores de otras lenguas ${ }^{9}$.

Cristòfor Despuig (1557) rechaza también el uso del latín y del castellano, aunque por razones muy distintas:

No he volgut escriure-la en llengua castellana per no mostrar tenir en poc la catalana, i també per no valer-me de llengua estranya per a llustrar i defensar la naturalesa pròpia, que és la principal intenció de montreball; ni tampoc la he volguda esciure en llatina perquè no pareguera ser tan generalment tractada i entesa per los de nostra nació com jo volguera, per honra i contentament dels quals s'és escrita. (Despuig 1996: 43)

Entonces, no escribe en latín porque entre los catalanes no es tan generalmente conocido, lo cual implica también que efectivamente a mediados del siglo XVI ya no se puede hablar de una diglosia latín-romance, ya que al latín ya le falta distribución para competir con el catalán. Por otra parte, para el no uso del castellano, Despuig emplea justamente un argumento propio de una situación diglósica pero cuya existencia muchos autores niegan. Afirma que el uso del castellano significaría desprestigiar al catalán, algo que varios autores, como hemos visto, niegan para justificar el empleo del castellano. A continuación, además, Despuig (1996: 53) se posiciona en contra del uso del castellano en general entre los catalanes:

I no dic que la castellana no sia gentil llengua i per tal tinguda, i també confesse que és necessari saber-la les persones principals, perquè és l'espanyola que en tota Europa se coneix, però condemne i reprove l'ordinàriament parlar-la entre nosaltres, perquè d'açò se pot seguir que poc a poc se lleve de rael la de la pàtria, i així pareixeria ser per los castellans conquistada.

Despuig compara el cambio de lengua casi con una subordinación al reino vecino, lo cual es justamente lo contrario de lo que se pretende en las batallas literarias. Se podría inferir que adoptando el castellano, el autor les daría la razón a los autores castellanos que desprestigian las otras lenguas ibéricas por su poca utilidad, por lo que la única forma de dignificar al territorio propio es emplear también su lengua.

El portugués Manoel de Galhegos establece una argumentación muy parecida para su lengua al criticar a los que abandonaron el portugués y 
afirma que fueron ellos quienes han provocado que hoy en día se podría mirar en menos al portugués:

A lingua portuguesa, como não heoge a que domina, esquecerãose della os engenhos, que com seus escritos a podião enriquecer, e autorizar: e quem agora se atreve a sahir ao mundo com hum livro de versos em Portuguez arriscase a parecer humilde, pois escreve numa lingua, cujas frasis, e cujas vozes se usão nas praças; o que não deixa de ser embaraço para a altiveza; que as palavras, de que menos usamos, soão bem, e a gradão em tazão da novidade, e por isso os retoricos lhe chamão peregrinas. (Galhegos 1635: sin paginación)

El catalán Andreu Bosch (1628: 26-27) entrega tres razones por las cuales escribe en catalán y no en alguna otra lengua, específicamente latín y castellano:

Primerament, per seguir los preceptes, y ensenyansa dels Hebreus, Caldeus, Foenicios, Graechs, Latins, Alarbes, y altres tots los quals donan per falta escriurer les memories de llurs terres, ab altra llengua que la materna puix la necessitan saber tots los estats, ygnorants, y Doctes.

Segonament, per lo concell del Pare del bon parlar, y eloquencia Cicero que dona per imperfet, $y$ de poch profit lo traball que nos escriu ab la propia llengua de la materia.

Tercerament, per contenir lo institut del present llibre materia sabuda per los savis, entesos, y curiosos, y per ells fora estat superfluo, y necedat escriure tocant me a mi de ells esser ensenyat, sols es estat per los qui comensan a professar, y entendrer, y per los mes ygnorants, per ensenyansa del estat, y titol gosa qui feu del menor al major, en los nostres Comtats, y dels fets nobilissims de les Patries, nacio, y sanch, per los quals fora estada falta manifesta, sino fos estada ab la llengua acomodada al entendre, ab conceptes clars yguals de la materia pera tots. Que altrament en Deo confio la aguera poguda traurer, en Llati, o Castellà.

La argumentación de Bosch se reduce principalmente a la conexión de la lengua con el territorio tratado en el texto. Con referencia a Cicerón explica que el trabajo queda imperfecto si la lengua no coincide con la materia de la obra. Además, Bosch deja entrever que la obra se debería dirigir principalmente a los propios habitantes del territorio tratado y el mayor número posible de ellos debería poder leerlo. Con lo anterior se refiere a los no cultos pero sí letrados que no serían capaces de leer su tratado en otra lengua que no fuese su propia materna. Para Bosch, además, la lengua no es un simple vehículo de transmisión sino parte de la alabanza que uno hace a una materia o territorio. Con ello coincide con autores antes referidos que escriben en castellano y que también consideran la lengua una excelencia 
del territorio. Sin embargo, ellos difieren de Bosch al considerar que dichas alabanzas se pueden expresar en castellano, sin que esto implique un menosprecio hacia la lengua propia. Por ello, afirma Bosch, en cambio, que si hubiese escrito en castellano, dicho hecho significaría "gloria y estimacio" (Bosch 1628: 27) para Castilla, lo cual no es la intención de su trabajo.

El cronista portugués Bernardo de Brito se posiciona también claramente en contra del uso de otras lenguas. En el prólogo del primer tomo de la Monarchia Lusytana (1597) relata que algunos amigos le aconsejaron redactar su obra en latín por su propia reputación y para su mayor divulgación. Brito rechaza esa opción alegando que con ello, si bien ganaría fama entre los extranjeros, la perdería entre los naturales, es decir, los portugueses que no dominan el latín. Igual que Bosch da preferencia a conseguir el mayor número de lectores dentro de su reino. Otros le dieron el consejo de publicar en castellano, el cual aparte de ser entendido en todos los reinos de España y muchos fuera de ella "me livrava da grosseria, \& ruim methodo de historiar da Portuguesa". La postura de de Brito (1597: 4) acerca de ello es contundente:

Mas como esta opinião era tão mal fundada, que nem sombra tinha de boa, nunca fiz rosto a quem ma persuadia. Vendo que a primeira rezão me arguya de interesseiro, em pretender gasto da impressão, \& a segunda de indigno de nome Portugues, em ter tão pouco conhecimento da lingoa propia, que a julgasse por inferior á Castelhana: sendo tanto pello contrario, que não ha lingoa em Europa (tomada nos termos que oje vemos) mais digna de se estimar pera historia, que a Portuguesa.

$\mathrm{Al}$ igual que Despuig, Brito señala que para honrar una lengua no basta con decirlo sino que es necesario escribir en ella para probarlo. Cinco años más tarde, en 1602, Brito reafirma esa posición en su primera parte de la Crónica de Cister. Argumenta que no tiene por qué disculparse por algo, ya que cada uno escribe como se lo comunica la naturaleza. Su visión todavía se encontraría "conforme com o da primeira parte da Monarchia, que anda impressa". (Brito 1602: sin paginación)

Jeroni Pujades (1609: sin paginación) también conecta la lengua al contenido de su obra, la cual es una crónica sobre Cataluña. Igual que Brito relata que se le propuso redactar la obra en castellano. Pujades lo rechaza de la siguiente forma: "Pero no es estata posible altra cosa, del que se es fet. Axi per no ser ingrat à la Patria y nacio: dexant la propia per altra llengua, y lo natural do per las gracies estranyes: com tambe per fer tota la obra de Cathalunya". En el caso de Pujades, sin embargo, la elección lingüística parece estar conectada al contenido y al propósito más bien que a principios, lo cual contradice la interpretación de Miralles referida al principio. En 
1621, doce años después de publicar la crónica, el autor explica en su Discurso sobre la justa assistencia de los Consellers de la fidelissima ciudad de Barcelona y Syndicos de la Generalidad de Barcelona al juramento prestado a los quinze de Abril deste año 1621, por el Excelentissimo Señor don Fernando Afán de Ribera y Henriquez, Duque de Alcalá, por qué ha decidido escribir en castellano. Como el discurso está dedicado al duque, cuya lengua es el castellano, sería apropiado escribir también en dicha lengua. Además, quisiera que su discurso fuera "entendido de naturales y estraños" (Pujades 1621: sin paginación). Entonces, Pujades aplica dos justificaciones: la conexión con la temática y el personaje de la dedicación, por una parte, y por otra el ya conocido argumento de la universalidad.

\section{CONCLUSIÓN}

Al analizar el fenómeno de la diglosia literaria en Cataluña, Valencia y Portugal durante los siglos XVI y XVII se pueden evidenciar tanto similitudes como diferencias. En cualquier caso, resulta necesario realizar un estudio comparativo de estos tres territorios, debido a que en esta temática han sido investigados de forma individual.

Retomando la primera hipótesis planteada podemos constatar que en los tres casos, la lengua cumple una función de característica de un territorio y sirve para enaltecer el mismo. Por una parte, se rechazan argumentos y prejuicios que existen contra la lengua propia y, según los cuales no serían una lengua digna para todos los ámbitos, por lo que tendría también menos validez y prestigio que el castellano. Varias de estas defensas se realizan en castellano, en cuyo contexto los autores suelen afirmar que esto no implica ninguna desvaloración de su propia lengua.

Por otra parte, se encuentran alabanzas y exaltaciones de la lengua propia, a veces caracterizándola como una lengua de grandes excelencias, otras incluso como la mejor lengua y explícitamente mejor que la castellana, es decir, la lengua de prestigio de facto. Estos dos tipos principales de afirmaciones hacia la lengua se encuentran en los tres territorios analizados.

Podemos concluir que efectivamente dichas alabanzas hacia la lengua se pueden ubicar en el contexto de las batallas preeminenciales literarias, ya que se usan de forma muy parecida que otros campos temáticos como la historia, el clima, la calidad de la tierra entre otros. Algunos autores como Sousa de Macedo, Bosch o Corbera tratan en sus obras respectivas todo tipo de excelencias con el fin de mostrar la dignidad y nobleza de su territorio 
por encima de todos los demás y uno de los criterios que aplican para ello es efectivamente la lengua del territorio.

Respecto a la segunda hipótesis, se evidencia una diferencia fundamental entre el caso del Reino de Valencia, por una parte, y Cataluña y Portugal, por otra. Ya en el siglo XVI resulta ser una posición muy minoritaria para autores valencianos publicar en su propia lengua. La gran mayoría opta por publicar en castellano y lo justifica así en sus prólogos, aludiendo entre otros argumentos a la mayor difusión de aquella lengua.

Esta posición también se encuentra entre autores catalanes y portugueses, tanto en el siglo XVI como en el XVII. Sin embargo, en estos dos territorios se halla también la fuerte presencia de una posición contraria. Muchos autores justifican la elección de su propia lengua, argumentando que de no hacerlo estarían menospreciándola. Otros argumentos empleados son el vínculo entre lengua y territorio que se quiere mantener y el querer llegar al público alfabetizado pero que no domina el castellano ni mucho menos el latín.

Ambos grupos consideran que su postura está en coherencia con el objetivo de glorificar el territorio. Los autores que publican en castellano no ven ninguna contradicción en alabar su lengua propia usando otra. Varios incluso afirman que al escribir en castellano contribuyen más a la glorificación de su territorio, ya que su obra le llegaría a un mayor número de lectores. Esta posición resulta viable, ya que la lengua no constituía un factor identitario como ocurre en los Estados nacionales de los siglos XIX y XX, lo cual converge con el hecho de que el nombre de una lengua hacía más referencia a donde se hablaba que de donde provenía. En este sentido, ya el autor anónimo de la Útil y breve institución para aprender los principios y fundamentos de la lengua española explica por qué emplea el término español para el castellano: "no porque en toda España se hable una sola lengua que sea universal, porque hay otras muchas lenguas, sino porque la mayor parte de España la habla". (1555/1977: 4, ver también Lledó-Guillem 2018: 125)

Los defensores del uso de la lengua propia, en cambio, no ven viable mostrar su lengua como una excelencia de su territorio cuando esta alabanza no está escrita en este mismo idioma. El uso del castellano les significa implícitamente una subordinación de su territorio bajo Castilla, una idea diametralmente opuesta al propósito que solían perseguir con sus obras que era mostrar la excelencia del suyo, muchas veces expresamente por encima de Castilla. También esta posición resulta viable por la percepción expuesta por los autores acerca del uso de la lengua. Si bien quizás no es un factor identitario tan relevante, sí es una característica muy importante del territorio y en este sentido para estos autores su uso sí incide en la reputación. 


\section{REFERENCIAS BIBLIOGRÁFICAS}

AldeRETE, BeRnARDO DE. 1606/1993. Del origen y principio de la lengua castellana ò romance qui oi se usa en España. Madrid: Visor.

Alonso Romo, Eduardo Javier. 2000. Los escritos portugueses de San Francisco Javier. Braga: Universidad do Minho.

Alves Moreira, Filipe. 2014. O papel da língua e do bilinguismo. En Luis Adão da Fonseca (coord.). Entre Portugal e a Galiza (Sécs XI a XVII). Um olhar peninsular sobre a região histórica, pp. 381-383. Porto: CEPESE and Fronteira do Caso Editores.

ANóNImo. 1555/1977. Útil y breve institución para aprender los principios y fundamentos de la lengua española. Madrid: Consejo Superior de Investigaciones Científicas.

Arraiz, Amador. 1604. Diálogos. Coimbra: Diogo Gomez Lovreiro.

BAHNER, Werner. 1956. Beitrag zum Sprachbewusstsein in der spanischen Literatur des 16. und 17. Jahrhunderts. Berlín: Rütten und Loehning.

Barbosa Homem, Pedro. 1627. Discursos de la juridica, y verdadera razon de estado, formados sobre la vida, y acciones del Rey don Juan el II de buena memoria, Rey de Portugal, llamado vulgarmente el Principe Perfecto. Coimbra: Nicolau Carvalho.

Barellas, Estevan. 1600. Centuria, o Historia de los famosos hechos del gran Conde de Barcelona don Bernardo Barcino. Barcelona: Sebastian de Comellas.

Beuter, Antoni. 1538/1995. Primera part de la Història de València. Valencia: Generalitat valenciana.

1563 [1546]. Primera parte de la Corónica general de toda España, y especialmente del reyno de Valencia. Valencia: Ioan Mey Flandro.

BinotTi, LuCia. 1995. La teoria del "castellano primitivo”: nacionalismo y reflexión lingüistica en el renacimiento español. Münster: Nodus-Publikationen.

Bosch, Andreu. 1628. Summari, Index, o Epitome dels Admirables, y Nobilissims Titols de Honor de Cathalunya, Rossello, y Cerdanya. Perpiñán: Pere Lacavalleria.

Bouza Álvarez, Fernando. 2009. Dar Galicia y el gallego a la imprenta. As Galegadas y A História de Galicia de Lobariñas Feijoo, la Verdadera Descripción de Ojea y algunas iniciativas historiográficas de la primera mitad del siglo XVII. Obradoiro de Historia Moderna 18: 9-44.

Brito, Bernardo De. 1597. Monarchia Lusytana, parte primeira. Alcobaça: Francisco de Santa Clara.

1602. Primeyra parte da Chronica de Cister. Lisboa: Pedro Crasbeck.

Buescu, ANA IsABel. 2004. Aspectos do bilingüismo português-castelhano na época moderna. Hispania LXIV/1, № 216: 13-38.

CARbonell, Jordi. 1979. Elements d'història social i política de la llengua catalana. Treballs de sociolingüística catalana 2: 87-102.

CARdim, Pedro. 2013. Portugal na monarquia hispânica: dinâmicas de integração e conflito. Lisboa: Centro de História de Além-Mar.

Carvalhão Buescu, Maria Leonor. 1983. Babel ou a ruptura do signo. A gramática e os gramáticos portugueses do século XVI. Lisboa: Imprenta Nacional - Casa da Moeda.

CASTRO, Ivo. 2002. Sur le bilinguisme littéraire castillan-portugais. En Francisco Bethencourt (coord.). La littérature d'auteurs portugais em langue castillane, pp. 11-23. Lisboa, Paris: Fundação Calouste Gulbenkian.

Cepada, Francisco. 1643. Resumpta historial de España desde el diluvio hasta el año de 1642. Madrid: Taço.

Colon I Domènech, Germà. 1978. La llengua catalana en els seus textos. Barcelona: Curial. 
Corbera, Estevan DE. 1678. Cataluña Ilustrada. Nápoles: Antonio Graminani.

Dangler, JeAn. 2001. Meditating fictions. Literature, women healers, and the Go-Between in Medieval and Early Modern Iberia. Londres: Associated University Presses.

Despuig, Cristòfor. 1996. [1557). Los col-loquis de la insigne ciutat de Tortosa. Barcelona: Biblioteca Ebrenca.

Domenec, ANTONio Vicente. 1602. Historia general de los santos y varones ilustres en santidad del Principado de Cataluña. Barcelona: Gabriel Graells y Giraldo Dotil.

Elliott, John H. 1992. A Europe of composite monarchies. Past and Present 137: 48-71.

Escartí, Vincent Joser. 1995. Introducción. En Antoni Beuter. Primera part de la Història de València (València 1538). Segunda parte de la Corónica General (València 1604), Valencia: Generalitat valenciana.

Esteba Ramos, Diana. 2002. El paradigma verbal en la Breve y Útil Institución de 1555. Interlingüística 13 (2): 41-52.

Faria e Sousa, Manuel De. 1678. Europa Portuguesa, Tomo I. Lisboa: Antonio Craesbeeck de Mello.

FASOLd, RALPH. 1996. La sociolingüistica de la sociedad. Introducción a la sociolingüistica. Madrid: Visor Libros.

Ferguson, Charles. 1959. Diglossia. Word 15: 325-340.

Ferreira de Lacerda, Bernarda. 1618. España libertada. Lisboa: Pedro Crasbeeck. 1634. Soledades de Buçaco. Lisboa: Mathias Rodrigues.

Fishman, Joshua. 1967. Bilingualism with and without diglossia; diglossia with and without bilingualism. Journal of Social Issues 32: 29-38.

1972. The sociology of language. Rowley: Newbury House.

Frías, Damasio De. 1929. Diálogos de diferentes materias inéditos hasta ahora. Madrid: Hernández y Galo Sáez.

Galhegos, Manoel De. 1635. Templo da memoria. Lisboa: Lourenço Craesbeek.

Glö̈L, Matthias. 2014. Monarquía imaginada - Eine Untersuchung zu Vorstellungen von der Monarchie auf der iberischen Halbinsel im 16. und 17. Jahrhundert. Hamburgo: Verlag Dr. Kovac.

2017. The Tubal figure in Early Modern Iberian historiography, $16^{\text {th }}$ and $17^{\text {th }}$ century. Imago Temporis XI: 27-51.

2020. Las "Flores de España, excelencias de Portugal" de António de Sousa de Macedo: una reinterpretación de la obra. Revista História Unisinos 24 (1): 34-44.

Guitarte, Guillermo. 1986. La dimensión imperial del español en la obra de Alderete: sobre la aparición del español de América en la lingüística hispánica. En Antonio Quilis y Hans Josef Niederehe (cords.). The history of linguistics in Spain, pp. 129-187. Amsterdam: John Benjamins.

Herrera, Fernando De. 1580. Anotaciones a las Obras de Garci Lasso de la Vega. Sevilla: Alonso de la Barrera.

Iorba, Dionysio Hieronymo De. 1589. Descripcion de las excellencias de la muy insigne ciudad de Barcelona. Barcelona: Hubertum Gotard.

Lledó-Guillem, Vincente. 2008. Literatura o imperio: la construcción de las lenguas castellana y catalana en la España renacentista. Newark: Juan de la Cuesta.

2018. The making of Catalan linguistic identity in Medieval and Early Modern times. Cham: Palgrave Macmillan.

López Madera, Gregorio. 1601. Discursos de la certidumbre de las reliquias descubiertas en Granada desde el año de 1588 hasta el de 1598. Granada: Sebastián de Mena. 
Magalhães De Gândavo, Pêro De. 1574/1981. Regras que ensinam a maneira de escrever e a ortografia da língua portuguesa. Com o diálogo que adiante se segue em defensão da mesma língua. Lisboa: Biblioteca Nacional.

Marfany, JoAn Lluís. 2001. La llengua maltractada. El castellà i el català a la Catalunya del segle XV al segle XIX. Barcelona: Empúries.

2008. Llengua, nació i disglòssia. Barcelona: L'Avenç.

Meisenburg, Trudel. 1998. Portugiesisch - ganz schön schwer? Zum Diálogo em defensão da lingua portuguesa von Pêro de Magalhães de Gândavo. En Martin Hummel y Christina Ossenkop (coord.). Lusitanica et Romanica. Festschrift für Dieter Woll, pp. 97-106. Hamburgo: Buske.

Mignolo, Walter. 1995. The darker side of the Renaissance: literacy, territoriality, and colonization. Ann Arbor: University of Michigan Press.

Miralles, Eulàlia. 2010. Sobre Jeroni Pujades. Barcelona: Institut d'Estudis Catalans.

Nagore, Francho. 1977. Gramática de la lengua aragonesa. Zaragoza: Librería General.

Ortí, Marco Antonio. 2005. Siglo quarto de la conquista de Valencia. Valencia: Ayuntamiento de Valencia.

PAs, Àngel De. 1579. Primera parte de los discursos espirituales sobre la inscripción, prólogo, y quatro primeros capítulos de la regla de los terceros. Barcelona: Pedro Malo.

Pastor, José Francisco. 1929. Las apologías de la lengua castellana en el siglo de oro. Madrid: Compañía Iberoamericana de Publicaciones.

Peña Díaz, Manuel. 1997. El castellano en la Cataluña de los siglos XVI y XVII. Manuscrits 15: 149-155.

Pitarch, Vicent. 1972. Defensa de l'idioma, Valencia: Tres i Quatre.

2000. Nota sobre la qüestió de la llengua al barroc: dues perspecives des de la talaia tortosina. Jornades de la Secció Filològica de l'IEC a Tortosa. Barcelona: Institut d'Estudis Catalans. 49-59.

Ponç D'ICARD, Lluis. 1572. Libro de las grandezas y cosas memorables de la Metropolitana Insigne y famosa Ciudad de Tarragona. Lleida: Pedro de Robles y Juan de Villanueva.

Pujades, Jeroni. 1609. Coronica Universal del Principat de Cathalunya. Barcelona: Hieronim Margarit.

1621. Discurso sobre la justa asistencia de los Consellers de la fidelissima ciudad de Barcelona y Syndicos de la Generalidad de Barcelona al juramento prestado a los quinze de Abril deste año 1621, por el Excelentissimo Señor Fernando Afán de Ribera y Henriquez, Duque de Alcalá. Barcelona.

Rodrigues Lobo, Francisco. 1990. Corte na aldeia. Lisboa: Ulisseia.

Rubio GonzÁlez, LoRenzo. 1988. Damasio de Frias. Un clásico para ser estudiado. Castilla: Estudios de Literatura 13: 145-158.

Severim de Faria, Manuel. 1624. Discursos vários políticos. Évora: Manoel Carvalho.

Simon I TARRÉs, ANTONI. 2005. Construccions polítiques i identitats naiconals. Catalunya i els origens de l'estat modern espanyol. Barcelona: Publicacions de l'Abadia de Montserrat.

Sousa de Macedo, António de. 1631. Flores de España, excelencias de Portugal. Lisboa: Jorge Rodriguez.

Spolsky, Bernard. 2011. Ferguson and Fishman: Sociolinguistics and the Sociology of Language. En Ruth Wodak et al. (coord.). The SAGE Handbook of Sociolinguistics, pp. 11-23. Londres: SAGE Publications.

Teruelo NúÑez, María Sol. 1985. Bilingüismo literario en Portugal. En Universidad de Oviedo (coord.). Homenaje a Álvaro Galmés de Fuentes. Tomo I, pp. 317-334. Madrid: Editorial Gredos. 
Torrent, Anna Maria. 1989. Llengua i poder polític a Catalunya al segle XVII. En Actes del Vuité Col·loqui Internacional de Llengua i Literatura Catalanes /II. Barcelona: Publicacions de l'Abadia de Montserrat. 29-55.

Torres SANS, Xavier. 2004. A vueltas con el patriotismo. La revuelta catalana contra la Monarquía Hispánica (1640 - 1659). En Antonio Álvarez-Ossorio Alvariño y Bernardo García García (coord.). La monarquía de las naciones. Patria, nación y naturaleza en la monarquía de España, pp. 811-844. Madrid: Fundación Carlos de Amberes.

Tres, JoAn. 1996. Introducció. En Cristòfor Despuig. Los col-loquis de la insigne ciutat de Tortosa. Barcelona: Biblioteca Ebrenca.

Vall-Llosera, August Rafanell. 1991. Un nom per a la llengua. El concepte de llemosi en la història del català. Vic: EUMO Editorial.

Valladares, Rafael. 2000. Portugal y la Monarquía Hispánica, 1580-1668. Madrid: Arco Libros.

VÁsquez Cuesta, Pilar. 1988. A língua e a cultura portuguesa no tempo dos Filipes. Lisboa: Publicações Europa-América.

VICIANA, MARTí DE. 1574. Libro de alabanças de las lenguas hebrea, griega, latina, castellana y valenciana. Valencia: J. Navarro.

Vilavedra, Dolores. 1999. Historia da literatura galega. Vigo: Galaxia. 